\title{
A mucosa-associated lymphoid tissue (MALT) lymphoma of the small intestine that was difficult to diagnose endoscopically
}

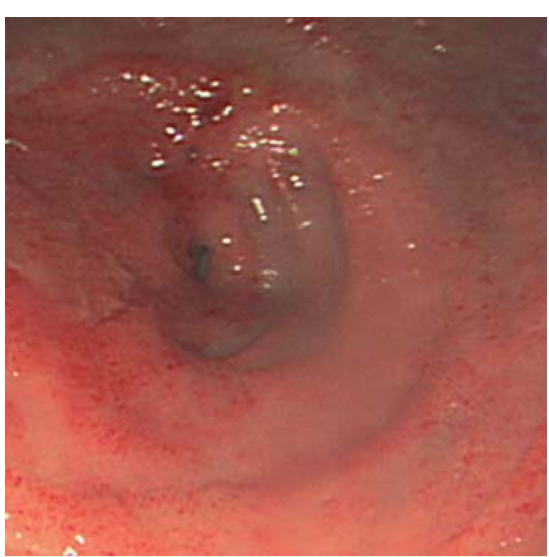

Fig. 1 The first enteroscopy showing a stricture $120 \mathrm{~cm}$ distal to the pylorus. There is irregularity of the small-bowel mucosa, but with no ulceration.

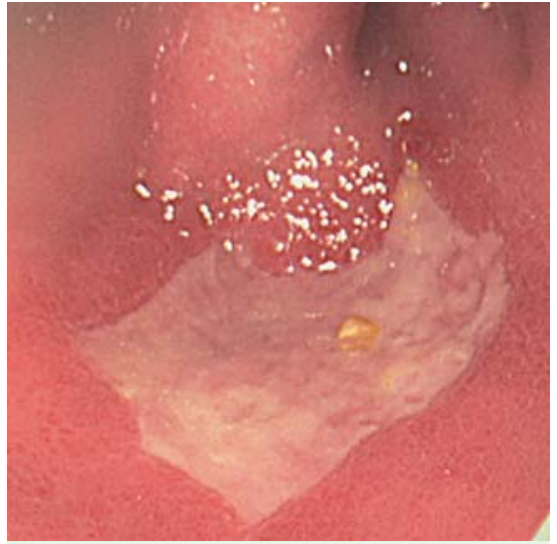

Fig. 2 The second enteroscopy showing a shallow ulcer on the proximal side of the stricture.
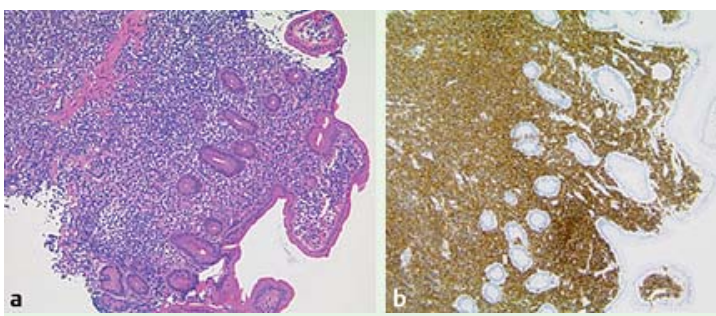

Fig. 3 a Histological section showing interstitial atypical lymphoid hyperplasia and lymphoepithelial lesions. The cells were positive for b CD20 and c CD79a.

A 75-year-old man was admitted with bloating, distension, and diarrhea since the past 2 months. He was not taking nonsteroidal anti-inflammatory agents (NSAIDs) on a regular basis. Abdominal computed tomography (CT) revealed a stricture in the jejunum. A small-bowel contrast study showed a severe stricture in the jejunum, which was dilated on its proximal side. Upper gastrointestinal endoscopy revealed gastritis and Helicobacter pylori. A colonoscopy revealed no abnormal findings. Oral single-balloon enteroscopy revealed a stricture $120 \mathrm{~cm}$ distal to the pylorus. Irregularity of the small-bowel mucosa was observed but there was no ulceration ( $\bullet$ Fig. 1). Histological examination of a biopsy specimen revealed interstitial atypical lymphoid hyperplasia.

Two weeks later, the patient was still symptomatic and a second enteroscopy was carried out for another biopsy specimen; during this procedure, a shallow ulcer was observed on the proximal side of the stricture ( $\bullet$ Fig. 2 ). The biopsy revealed a lymphoepithelial lesion that was positive for CD20 and CD79a ( Fig.3) and negative for CD10 and CD5. On the basis of these findings, the patient was diagnosed as having marginal zone B-cell lymphoma of mucosa-associated lymphoid tissue (MALT).

After antibiotic treatment for $H$. pylori eradication, the patient was treated with three cycles of rituximab and four cycles of rituximab plus R-CHOP (cyclophosphamide, doxorubicin, vincristine, and prednisolone) chemotherapy. A third enteroscopy showed that the ulcer had healed and the stricture had reduced in size (๑ Fig. 4).

In the present case, a change in the form of the lesion was observed within a short

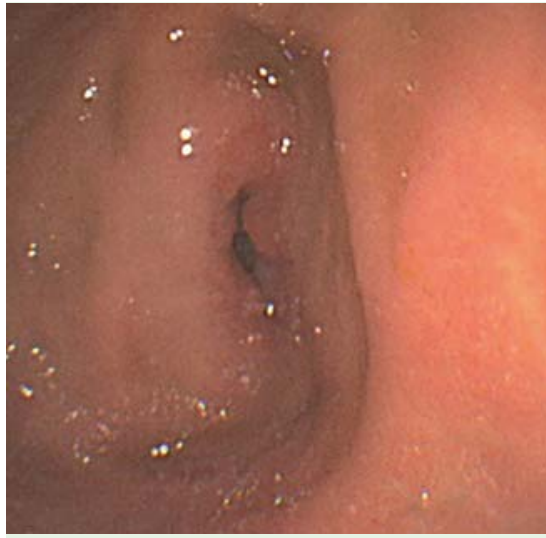

Fig. 4 The third enteroscopy carried out after chemotherapy showing absence of ulceration and reduced stricture.

time period, because of which a pathological diagnosis was possible. Although enteroscopy is widely used for detection and diagnosis, the procedure should be done more than once to obtain a reliable diagnosis.

\section{Endoscopy_UCTN_Code_CCL_1AC_2AC}

\section{K. Yoneda, H. Takahashi, Y. Abe, \\ M. Inamori, S. Kato, T. Uchiyama, \\ H. lida, H. Mawatari, K. Hosono,}

H. Endo, Y. Nozaki, T. Akiyama, K. Fujita, M. Yoneda, N. Kobayashi, H. Kirikoshi, K. Kubota, S. Saito, A. Nakajima Gastroenterology Division, Yokohama City University School of Medicine, Japan

\section{Bibliography}

DOI 10.1055/s-0029-1214857

Endoscopy 2010; 42: E175

(c) Georg Thieme Verlag KG Stuttgart · New York . ISSN 0013-726X

\section{Corresponding author}

\section{H. Takahashi}

Gastroenterology Division

Yokohama City University School of Medicine 3-9 Fuku-ura

Kanazawa-ku

Yokohama 236-0004

Japan

Fax: +81-45-7843546

hirokazu@med.yokohama-cu.ac.jp 